\title{
Su Jok Therapy for Managing Chest Pain During COVID-19 Pandemic Period: A Case Report
}

\author{
Intansari Nurjannah ${ }^{1 *}$ \\ 1 Associate Professor \\ Department of Mental Health and Community Nursing, Faculty of Medicine, Public Health and Nursing Universitas Gadjah Mada, Indonesia
}

\begin{abstract}
Background: The Covid-19 pandemic has led people who were non-COVID-19 patient to avoid hospital admission and to seek help from alternative medicine. The aim of this report is to describe the management of chest pain at home using Su Jok therapy. Case report: A male 47 of years old complained of chest pain with difficulty breathing and asked for help from the researcher who was a nurse as well as Su Jok therapist. His sclera profile was recorded for analysis (sclerology analysis). Su Jok therapy was applied directly by the researcher on daily basis. Researcher also monitored his condition progress through checking pain point on his hands and also from his sclera profile. After two weeks, the symptoms subsided and the eye's profile of sclera shows healing progress. Conclusion: The case study shows that $\mathrm{Su}$ Jok therapy may become an alternative therapy for managing chest pain.
\end{abstract}

Keywords: Su Jok, chest pain, scelorogy, COVID-19, pandemic

\section{Introduction}

The COVID-19 pandemic has caused many cases other than COVID were not managed in a timely manner for example in one hospital in Italy, 12 cases were late in getting access to health care during March 23-27 in 2020, and data in five hospitals showed that in the statistics for the period of 1-27 March, there was sharp decrease in the number of visitations in the pediatric emergency unit, with a drop in the range of $73 \%-88 \%$ [1].

In the United Kingdom, a national campaign of health policies requires the families to stay at home to avoid infection and this causes the parents to bring children to the hospital later than they should, so that morbidity and mortality sometimes cannot be avoided [2]. Another study states, based on a survey conducted in April 2020 also in the UK, a pediatric consultant said that in the second week of April they saw children who were late to be admitted to hospital, and this was due to the COVID-19 pandemic [3].

Delays in bringing patients for analysis related to cancer diagnosis also occurred in the United States due to COVID-19 [4] and this was also related to late diagnoses and delayed patient treatment [5]. In the field of ophthalmological emergencies, a decrease in visits to ophthalmological emergency department was also found, where in 2019 there were 2902 visits while in 2020 it decreased to 776 visits [6].

In Indonesia, the types of visits and consultations to clinics are also changing. The patients' family must consult by telephone to the clinic to find out whether the patient needs to be brought there to visit the clinic or not. Visitation by the patient's family or friends or neighbors to the hospital are also prohibited, and only one caregiver can accompany the patient who is being cared for at the clinic or hospital.

People in Indonesia are also advised to avoid going to a hospital or clinic and this has caused a drastic reduction in visits to the hospital. This may contribute to why people in Indonesia are also trying to find alternative treatments (complementary therapy) and learning to perform self-treatment at home, for example by using their own resources such as traditional herbal remedies or massage.

Regarding efforts to seek complementary alternative medicine during the COVID-19 pandemic, this article reports a case series concerning patients with chest pain using a complementary therapy: Su Jok. Su Jok is a therapy discovered by Prof. Park Jae Woo from South Korea in 1987. Su Jok comes from the Korean language where Su means hand and Jok means foot [7]. $\mathrm{Su}$ Jok therapy is performed by stimulating with massage, and applying colors, magnets, seeds, and other techniques at the points of the hands and or feet

*Corresponding author: intansarin@ugm.ac.id 
according to the location of the organs or body parts mapped in the hands and feet [8]. This is done because in the hands of the feet there is a map of all the organs and areas of the body on the hands and feet which is similar to the human body [7].

In this case study report the confirmation of the problem experienced by the patient was done using the method of checking through certain points based on the $\mathrm{Su}$ Jok map for the heart organ in the patient's hand, and also by using eye photo reading (sclerology). Monitoring of the patient's progress was also done similarly and primarily by analyzing the patient's sclera photograph.

Examination of the eye sclera is often referred to as sclerology which is defined as an art and science to interpret the red lines in the whites of the eyes [9]. Another reference states that sclerology is similar to iridology but interprets the size of the blood vessels in the white areas of the eye [10].

One study mentioned that the use of iridology and sclerology can provide a better understanding of diabetes [11]. Another experimental study found that sclerology has a diagnostic error of about $20 \%$ and $24 \%$ on average and can be used to diagnose and understand patterns of basic health data conditions of a person [12]. In this case report, considering the context of the COVID-19 situation and the limitations of diagnostic tools, sclerology is the easiest choice of detection tool to predict and monitoring the problems experienced by patients.

\section{Case Presentation}

A 47-year-old man complained of chest pain and difficulty breathing on the evening of July 15, 2020. The eye's profile showed the cross line which indicates blockage in blood vessels and the type of line which is called 'snake in the pipe' showing the elasticity of the blood vessels had decreased. This eye profile matched with his symptoms which are chest pain and difficulty to breath.

The therapy performed involved were correspondent therapy (therapy targeted to heart organ) and energy therapy (therapy targeted to energy/meridian). Researcher also checked his sclera profile regularly to be able to see the healing process. The summary symptoms and sujok therapy can be seen in table 1, while the glossary for use of abbreviations can be seen in table 2. After two weeks, the sclera shows a clear profile starting with a change in the line both in color thickness and the number of lines, while the snake line in the tube was greatly reduced and almost gone (Fig 9.).
Table 1. History of symptoms

\begin{tabular}{|c|c|}
\hline Date & Symptoms \\
\hline 15th July 2020 & $\begin{array}{l}\text { Left chest pain, heavy breathing } \\
\text { and shortness of breath }\end{array}$ \\
\hline 16th July 2020 & Complaints are gone \\
\hline 17th of July 2020 & Complaints are gone \\
\hline 18th July 2020 & Complaints are gone \\
\hline 19th July 2020 & $\begin{array}{l}\text { Feels tight in chest when he } \\
\text { works hard physically and } \\
\text { required a short breath before } \\
\text { continuing to do physically hard }\end{array}$ \\
\hline 20th July 2020 & No complaint \\
\hline 21th July 2020 & $\begin{array}{l}\text { Breath is little short, but no } \\
\text { chest pain (in the morning) }\end{array}$ \\
\hline 22th July 2020 & Sometimes feels short breath \\
\hline 23th July 2020 & No complaint \\
\hline 24th July 2020 & No complaint \\
\hline 25th July 2020 & No complaint \\
\hline 26th July 2020 & $\begin{array}{l}\text { Participated in heavy work } \\
\text { activities in the village but there } \\
\text { was no tightness and chest pain }\end{array}$ \\
\hline 27th July 2020 & $\begin{array}{l}\text { No complaint of chest pain and } \\
\text { shortness of breath }\end{array}$ \\
\hline 28th July 2020 & No complaint \\
\hline 29th July 2020 & No complaint \\
\hline 30th July 2020 & No complaint \\
\hline
\end{tabular}


Table 2. History therapy

\begin{tabular}{|c|c|}
\hline Date & $\begin{array}{c}\text { Therapy : } \\
\text { Time (M=Morning, D=Day, } \\
\text { N=Night)/Type of therapy }\end{array}$ \\
\hline 15th July 2020 & N/Ms, CRd, Mx, Hs, CR, Mg \\
\hline 16th July 2020 & M-D-N/SK, HS \\
\hline 17th of July 2020 & M-N/HS, SK \\
\hline 18th July 2020 & M-N/HS \\
\hline 19th July 2020 & M-N/HS, Ms, S \\
\hline 20th July 2020 & $\begin{array}{c}\text { M-D-N/Ms, CRd, Mx, CRO, N, } \\
\text { Mg, S }\end{array}$ \\
\hline 21th July 2020 & M-N/IT, Ms, Mg, CRd, S, N \\
\hline 22th July 2020 & $\mathrm{M} / \mathrm{Ms}, \mathrm{CRO}, \mathrm{Mx}, \mathrm{HS}$ \\
\hline 23th July 2020 & M-N/Ms, CRO, Mx, HS, SK \\
\hline 24th July 2020 & N/SK \\
\hline 25th July 2020 & $\mathrm{M} / \mathrm{Ms}, \mathrm{Mx}, \mathrm{HS}$ \\
\hline 26th July 2020 & $\mathrm{M} / \mathrm{HS}$ \\
\hline 27th July 2020 & M-N/Ms, Mx, M, SK \\
\hline 28th July 2020 & M-N/Ms, CRO, Mx, HS \\
\hline 29th July 2020 & $\mathrm{M} / \mathrm{Ms}, \mathrm{CRO}, \mathrm{Mx}, \mathrm{HS}$ \\
\hline 30th July 2020 & N/HS \\
\hline
\end{tabular}

Table 3. Su Jok area of therapy

\begin{tabular}{|c|c|}
\hline Date & Su Jok area of therapy \\
\hline 15th July 2020 & CMSH/TJ6/TJ14/NM \\
\hline 16th July 2020 & FM/TJ6 \\
\hline 17th of July 2020 & TJ6/FM \\
\hline 18th July 2020 & TJ14 \\
\hline 19th July 2020 & TJ14/CSSH/CMSH \\
\hline
\end{tabular}

\begin{tabular}{|c|c|}
\hline 20th July 2020 & $\begin{array}{c}\mathrm{CSSH} / \mathrm{CSIH} / \mathrm{CMSH} / \mathrm{CB} / \mathrm{CSp} / \\
\mathrm{NM}\end{array}$ \\
\hline 21th July 2020 & $\begin{array}{c}\mathrm{FM} / \mathrm{CMSH} / \mathrm{CB} / \mathrm{CSp} / \mathrm{CSSH} / \\
\mathrm{NM} /\end{array}$ \\
\hline 22th July 2020 & $\mathrm{CSSH} / \mathrm{CMSH} / \mathrm{TJ} 6$ \\
\hline 23th July 2020 & $\mathrm{CMSH} / \mathrm{CB} / \mathrm{CSp} / \mathrm{TJ} 6 / \mathrm{EP} / \mathrm{FM}$ \\
\hline 24th July 2020 & FM \\
\hline 25th July 2020 & $\mathrm{CSSH} / \mathrm{CISH} / \mathrm{CMSH}$ ?EP \\
\hline 26th July 2020 & TJ6 \\
\hline 27th July 2020 & $\mathrm{CSSH} / \mathrm{CISH} / \mathrm{CMSH} / \mathrm{EP} / \mathrm{FM}$ \\
\hline 28th July 2020 & CSSH/CMSH/TJ14/FTS \\
\hline 29th July 2020 & $\begin{array}{c}\mathrm{CSSH} / \mathrm{CMSH} / \mathrm{TJ} 6 / \mathrm{EP} / \mathrm{FTS} / \\
\mathrm{CSSH} / \mathrm{CMSH}\end{array}$ \\
\hline 30th July 2020 & FTS \\
\hline
\end{tabular}

Table 4. The glossary for use of abbreviation of the type of therapy

\begin{tabular}{|c|c|}
\hline Abbreviation & Meaning \\
\hline Su Jok type of therapy & $\begin{array}{c}\mathrm{CR}=\text { Color ring therapy } \\
\text { (with red) } \\
\mathrm{CRd}=\text { Color therapy with } \\
\text { red } \\
\mathrm{CRO}=\text { Color therapy with } \\
\text { orange } \\
\mathrm{HS}=\text { Homo sedation with } \\
\text { red color } \\
\mathrm{Mg}=\text { Magnet star } \\
\mathrm{Ms}=\text { Massage therapy } \\
\mathrm{Mx}=\text { Moxibustion therapy } \\
\mathrm{N}=\text { Nail therapy (red for } \\
\text { heart tonification) } \\
\mathrm{S}=\text { Seed therapy } \\
\mathrm{SK} \text { (Six ki for artery } \\
\text { blockage) (In meridian F, } \\
\text { sedate VI, tonify III, in } \\
\text { Meridian J sedate VI, in } \\
\text { meridian Y sedate VI and } \\
\text { tonify III) } \\
\mathrm{T}=\text { Twist }\end{array}$ \\
\hline
\end{tabular}


Table 5. The glossary for use of abbreviation of the target area of therapy

\begin{tabular}{|c|c|}
\hline Abbreviation & Meaning \\
\hline $\begin{array}{c}\text { Su Jok target area of } \\
\text { therapy }\end{array}$ & $\begin{array}{c}\mathrm{CB}=\mathrm{Correspondence} \mathrm{of} \mathrm{brain} \\
\text { (Figure 1) } \\
\text { CISH=Correspondence of } \\
\text { 2) } \\
\text { Insect System of Heart (Figure } \\
\text { CMSH=Correspondence of } \\
\text { mini system of heart (Figure 2) } \\
\mathrm{CSp}=\text { Correspondence of Spinal } \\
\text { Cord (Figure } 3 \text { ) } \\
\text { CSSH= Correspondence of } \\
\text { standard system of heart (Figure } \\
\text { 2) } \\
\text { EP = Energy point (Standard } \\
\text { system) (Figure 4) } \\
\text { FM = Finger meridians (Figure } \\
\text { 5) } \\
\text { FTS = Functional of } \\
\text { circulatory Triorigin } \\
\text { System (Figure 6) } \\
\text { NM = Nail meridian (heart } \\
\text { meridian) (Figure 7) } \\
\text { TJ14 = Triorigin number 14 } \\
\text { (Heart meridian) (Figure } 8 \text { ) } \\
\text { TJ6 = Triorigin number } 6 \\
\text { (Heart organ) (Figure } 8 \text { ) }\end{array}$ \\
\hline
\end{tabular}

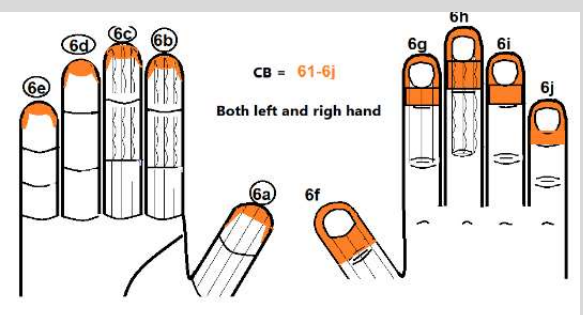

Fig. 1. Correspondence of brain

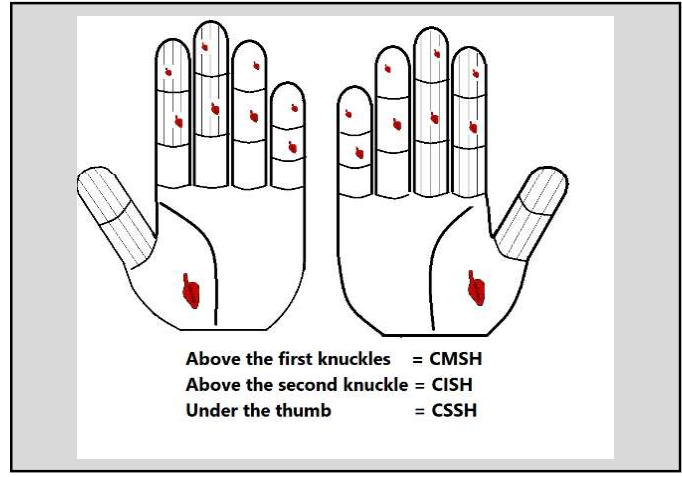

Fig. 2. Correspondence Standard System of Heart (CSSH), Correspondence Insect System of

Heart (CISH), Correspondence Mini System of Heart (CMSH)

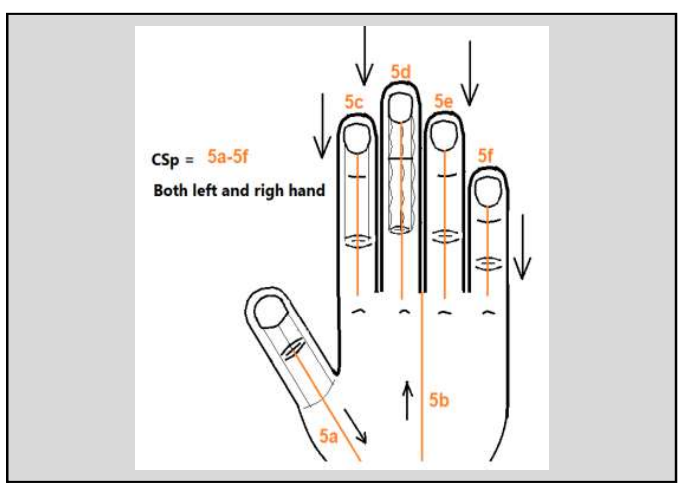

Fig. 3. Correspondence of Spinal Cord (CSp)

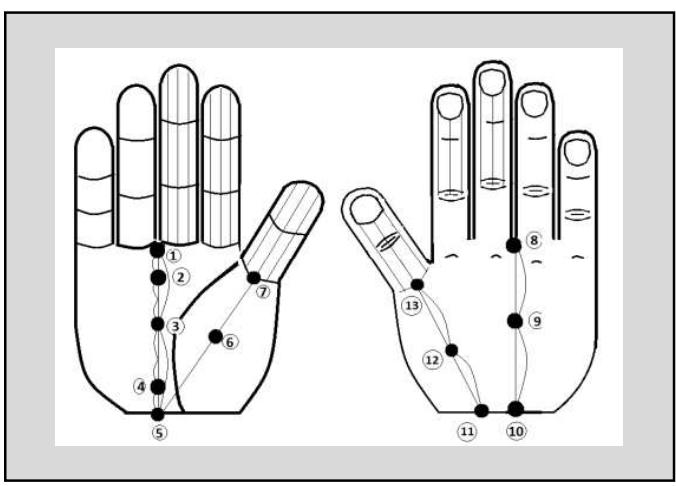

Fig. 4. Energy point (standard system) 


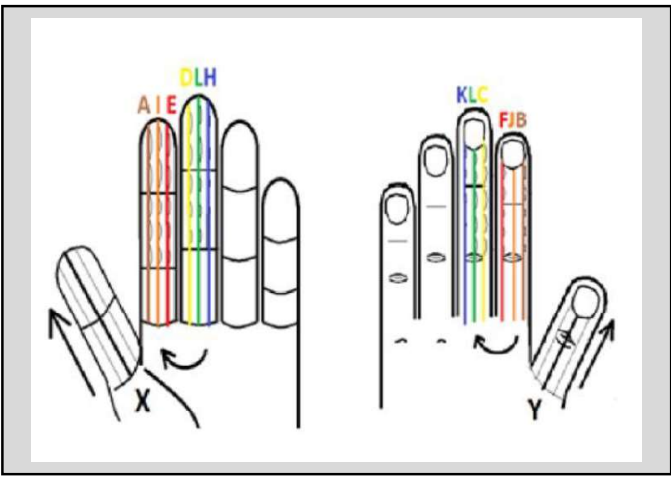

Fig. 5. Finger meridians

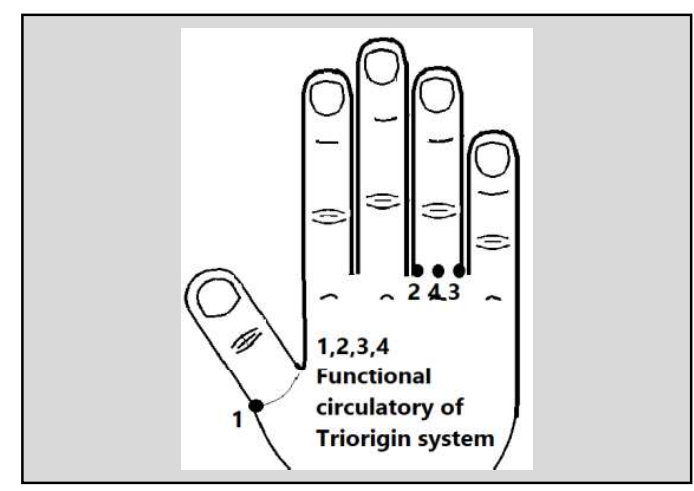

Fig. 6. Functional circulatory of Triorigin system

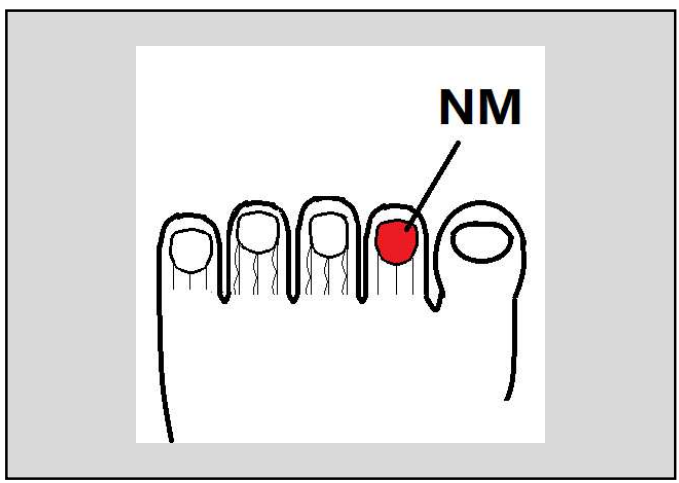

Fig. 7. Nail Heart Meridian (NM)

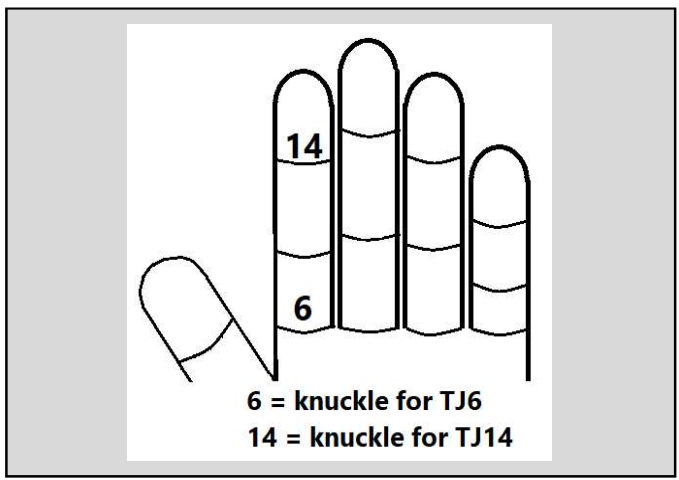

Fig. 8. Triorigin Heart Meridian (TJ 14) and heart organ Triorigin (TJ6)

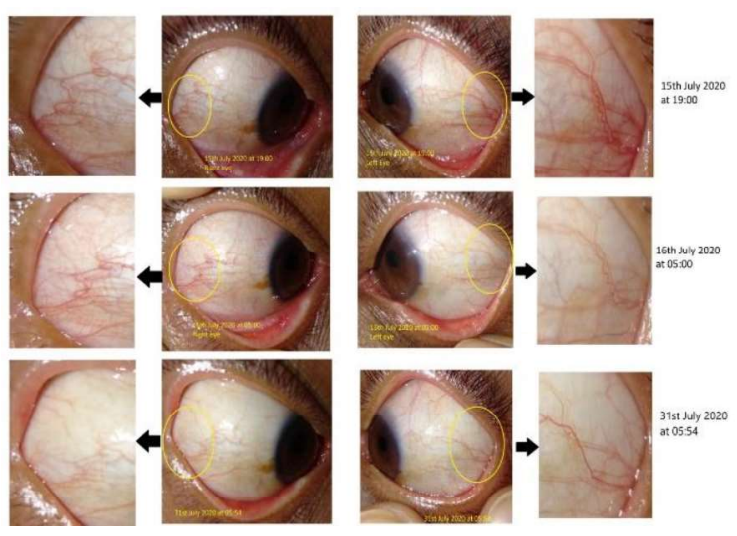

Fig. 9. The comparison of the sclera profile of second case on 15 th July, 16 July and 31st July 2020

\section{Discussion}

The eye's profile showed the cross line which indicates blockage in blood vessels and the type of line which is called 'snake in the pipe' showing the elasticity of the blood vessels had decreased. This eye profile matched with his symptoms which are chest pain and difficulty to breath.

The therapy performed was varied and adjusted to the patient's condition and symptoms. For example, on July 21 st 2020, when the patient felt mild shortness of breath, without chest pain, the researcher conducted therapy that did not target to the heart area but tonified the wind energy in the lung meridian. This tonification was done using green color to increase wind energy, which is the energy that is the main source of movement [13]. It is hoped that with the strengthening of the energy motion of the lungs, the breath will become lighter. In this case, after less than 10 minutes, the patient's shortness of breath was reduced.

The focus of Su Jok therapy is weakening (sedation) the coldness energy in both the corresponding points and the coldness sedation in the heart meridians. Coldness energy is chosen for sedation because this coldness energy is a characteristic of a blockage condition of the heart or blood vessels [13].

The body has 12 meridians and one of the meridians that was the focus of therapy in this case is the heart meridian [14]. Therapy for the heart meridian can be targeted using the meridian on the hands or on the toenails or by using the meridian in triorigin system. Triorigin is also a therapeutic technique invented by Prof. Park after the concept of Su Jok was introduced by him.

No less important than this therapy is a therapy that targets the heart organ, also known as correspondent therapy. The correspondent points of the heart itself can be found in several locations depending on what correspondence system is used. This is important when it is known, organically or physically, that the heart does have a problem.

After two weeks, the sclera shows a clear profile starting with a change in the line both in color thickness 
and the number of lines, while the snake line in the tube was greatly reduced and almost gone. Sclera also shows a healing and cleansing process as the body begins to adapt to achieve optimal health [9].

Although Su Jok therapy, in this case, was quite successful, the eye profile of the second case-patient showed a pattern in which his chest pain event could be re-experienced, and this was greatly influenced by life style choices such as nutritional consumption pattern, as well as the regularity in doing Su Jok therapy.

Therefore, the patient needs to check the condition of the heart regularly by analyzing the sclera profile especially in his left eye from two to four o'clock direction and on the right eye from eight to nine o'clock direction. This will also be a more complete approach by checking the pain points at the heart point in the correspondence of standard, insect, and mini system. The presence of a pain point indicates a heart problem. The combination of checking through the sclera profile and the corresponding heart pain points will provide clearer confirmation for therapeutic purposes.

There is a limitation however, in assessing eye profile, as eye profile is affected by light and also the tools or camera used for taking eye's profile. In this regard, the researcher tried to reduce this effect by using the same tool to take photographs of the eye.

\section{Conclusion}

Case studies have been reported showing that $\mathrm{Su}$ Jok therapy can reduce symptoms of chest pain. Su Jok therapy can be an easy and inexpensive alternative to therapy for those who need therapy without having to go to the hospital. Monitoring the condition of chest pain using sclera analysis (sclerology) is an important part of the Su Jok therapy in cases of chest pain. Visiting the hospital, however, is still necessary when the symptoms get worse.

\section{Consent for Publication}

Participant agreed to be published without any identification (anonymous).

\section{Conflict of Interest}

There is no conflict of interest in this publication.

\section{Acknowledgements}

Thanks go to Dr Minchul Park and Madam Bhupinder Kaur, my teacher in Su Jok class and Mr Arman Sibuea, my teacher in Sclerology class.

\section{References}

1. Lazzerini M, Barbi E, Apicella A, Marchetti F, Cardinale F, Trobia G. Delayed access or provision of care in Italy resulting from fear of COVID-19. The Lancet Child \& Adolescent Health. 2020;4(5):e10-e1.

2. Roland D, Harwood R, Bishop N, Hargreaves D, Patel S, Sinha I. Children's emergency presentations during the COVID-19 pandemic. The Lancet Child \& Adolescent Health. 2020;4(8):e32-e3.

3. Lynn RM, Avis JL, Lenton S, Amin-Chowdhury Z, Ladhani SN. Delayed access to care and late presentations in children during the COVID-19 pandemic: a snapshot survey of 4075 paediatricians in the UK and Ireland. Archives of disease in childhood. 2020;0(0):1-2.

4. Ding YY, Ramakrishna S, Long AH, Phillips CA, Montiel-Esparza R, Diorio CJ, et al. Delayed cancer diagnoses and high mortality in children during the COVID-19 pandemic. Pediatric Blood \& Cancer. 2020(e28427):1-3.

5. Richards M, Anderson M, Carter P, Ebert BL, Mossialos E. The impact of the COVID-19 pandemic on cancer care. Nature Cancer. 2020:13.

6. Pellegrini M, Roda M, Lupardi E, Di Geronimo N, Giannaccare G, Schiavi C. The impact of COVID19 pandemic on ophthalmological emergency department visits. Acta ophthalmologica. 2020;1:1-2.

7. Park J, W. Sujok for everybody. Jaipur, India: Su Jok Teherapy Centre; n.d.

8. Park J, W. Be your own doctor: Smile academy; 1987.

9. Tan C. Master of Sclerology. International Sclerology Institute; 2010 [cited 2020 13rd August]; Available from: https://iridologyresearch.com/wp-content/uploads/2018/07/tanmaster_sclerology.pdf.

10. Berret S. Iridology is Nonsense. 2010 [cited 2020 13rd August]; Available from: https://www.affordablecebu.com/forum/17-378-1.

11. Agarwal D, Bansal A. Non-invasive techniques for the screening of diabetic retinopathy. J Biomed Imag Bioeng. 2017;2(2):25-30.

12. Ryu KR. Scleral Diagnostic System Implementation with Color and Blood Vessel Sign Pattern Code Generations. 한국정보통신학회논문지. 2014;18(12):3029-34.

13. Park J, W. The Six Energy Theory Illustrated Handbook. Jaipur, India: Smile Academy Pvt. Ltd.; 2002.

14. Park J, W. Atlas of the energy system of the human body. Jaipur, India: Su Jok Therapy Center Pvt.Ltd; 2007. 